\title{
Posterior fixation of thoracolumbar burst fractures: Is it possible to protect one segment in the lumbar region?
}

\author{
Umut Canbek • Levent Karapınar • \\ Ahmet İmerci • Ulaş Akgün • Mert Kumbaracı • \\ Mustafa İncesu
}

Received: 31 May 2013/ Accepted: 24 September 2013/Published online: 5 October 2013

(C) The Author(s) 2013. This article is published with open access at Springerlink.com

\begin{abstract}
Background The treatment for thoracolumbar burst fractures is controversial. The aim of this retrospective study was to compare intermediate-segment (IS) and long-segment (LS) instrumentation in the treatment for these fractures.

Methods IS instrumentation was considered as pedicle fixation two levels above and one level below the fractured vertebra (infra-laminar hooks attached to lower vertebra with pedicle screws). LS instrumentation was done two levels above and two levels below the fractured vertebra. Among a total of 25 consecutive patients, Group 1 included ten patients treated by IS pedicle fixation, whereas Group 2 included fifteen patients treated by LS instrumentation.

Results The measurements of local kyphosis $(p=0.955)$, sagittal index $(p=0.128)$, anterior vertebral height compression $(p=0.230)$ and canal diameter expansion $(p=0.839)$ demonstrated similar improvement at the final follow-up between the two groups. However, there was a significant difference $(p<0.05)$ between Group 1 and Group 2 regarding clinical outcome [Hannover scoring
\end{abstract}

U. Canbek · U. Akgün

Department of Orthopaedics and Traumatology, Mugla Sitk1

Kocman University School of Medicine, Mugla, Turkey

e-mail: umutcanbek@hotmail.com

L. Karapınar · M. Kumbarac1 · M. İncesu

Department of Orthopaedics and Traumatology, Izmir Tepecik

Education and Research Hospital, Izmir, Turkey

e-mail: 1karapinar@yahoo.com

\section{A. İmerci $(\square)$}

Department of Orthopaedics and Traumatology, Erzurum

Palandöken State Hospital, Osmangazi mah, Emniyet Sok.

No. 35 Palandöken, 25000 Erzurum, Turkey

e-mail: ahmet_dr81@hotmail.com system, Oswestry disability questionnaire and the range of motion of the lumbar region compared to neutral $\left.\left(0^{\circ}\right)\right]$.

Conclusions The radiographic parameters were the same between the two groups. However, the clinical parameters demonstrated that IS instrumentation is a more effective management of thoracolumbar burst fractures.

Keywords Instrumentation - Thoracolumbar ·

Treatment

\section{Introduction}

Unstable fractures of the thoracolumbar spine often require internal fixation. Stabilisation of these injuries has many advantages, including early mobilisation of the patient and the potential for neurological improvement. The optimal treatment for these injuries is controversial.

The treatment modality that provides superior spinal canal restoration has not yet been conclusively identified [1, 2]. Various opinions exist regarding selection of the most effective surgical method to treat these fractures $[3,4]$. The current consensus about treatment of this type of fracture is to fix the fewest number of vertebrae and to provide a safe fixation and neural canal decompression [4-6].

Short-segment posterior instrumentation is currently the most frequently used treatment modality [4, 6, 7]. Methods that support the anterior column or long-segment posterior instrumentation are applied to eliminate inadequate reduction, loss of reduction and inadequate correction of the spinal canal, all of which may be encountered following short-segment posterior instrumentation [4, 6, 8-11]. Longsegment posterior instrumentation involves immobilisation of more vertebrae although it provides a better fixation and 
better spinal canal remodelling. We consider that the negative aspects of both long- and short-segment posterior instrumentation may be eliminated with intermediate-segment instrumentation.

The aim of this study was to evaluate and compare the radiological and functional results between intermediatesegment (IS) instrumentation and long-segment (LS) instrumentation via a posterior approach in the treatment of thoracolumbar burst fractures.

\section{Materials and methods}

\section{Subjects}

In this study, 37 out of 50 patients who had been surgically treated by a single surgeon for thoracolumbar vertebra fractures between 2000 and 2009 were evaluated. Four patients were eliminated from the study because they developed neurological deficits, and eight patients were excluded from the study because they did not return for control visits, although they were invited. A total of 25 patients ( 14 females and 11 males) were retrospectively evaluated. Fourteen out of 25 patients had a type B fresh thoracolumbar burst fracture according to the Denis classification at L1, seven at T12 and four at L2 [12]. Injury involved all three columns. Patients were divided into two groups according to the type of surgery. Group 1 (IS instrumentation and fusion) included 10 patients (6 females and 4 males), and Group 2 (LS instrumentation and fusion) included 15 patients ( 8 females and 7 males). The mean ages of the patients were 32.3 years (range 17-52) and 36 years (range 19-50) in Group 1 and Group 2, respectively (Table 1 ).

\section{Surgical technique}

Urgent decompression and vertebral alignment are required in the presence of neurological deficits. While some authors recommend the surgery when the patient is stable, some others prefer to wait for 4 days or longer until posttraumatic swelling decreases. All of our patients were operated on within the first $24 \mathrm{~h}$ after injury. A posterior approach to the thoracolumbar vertebrae is a well-described and accepted surgical procedure.

Table 1 Descriptive characteristics of the research group

\begin{tabular}{lll}
\hline & $\begin{array}{l}\text { Intermediate segment } \\
\text { (IS) }\end{array}$ & $\begin{array}{l}\text { Long segment } \\
\text { (LS) }\end{array}$ \\
\hline $\begin{array}{l}\text { Age (years) } \\
\begin{array}{l}\text { Follow-up period } \\
\text { (months) }\end{array}\end{array}$ & $32.3(17-52)$ & $36(19-50)$ \\
\begin{tabular}{l} 
Gender (F/M) \\
\hline
\end{tabular} & $6 / 4$ & $70.46(51-102)$ \\
\hline
\end{tabular}

Posterior instrumentation with fusion was used for vertebral surgery in our clinic. Adequate surgical exposure was performed via posterior midline incision. Pedicle screws were placed in accordance with surgical technique. If 2-1 instrumentation was performed, four trans-pedicular screws were inserted into the two vertebrae cranial to the fractured vertebra, two trans-pedicular screws were inserted into the one vertebra caudal to the fractured vertebra, and two laminar hooks were inserted into both laminae of the same vertebra on the caudal side (Fig. 1a, b). In the case of 2-2 instrumentation, a total of eight screws were inserted into two vertebrae cranial and caudal to the fractured vertebra (Fig. 2a, b). Considering the distraction that would be performed thereafter, two rods of appropriate size were chosen according to the instrumentation level. The rods were bound to each other using transverse connectors at a minimum of two levels, and strong stabilisation was provided sagittally, frontally and rotationally. Decompressive laminectomy was not performed.

Sagittal deformities that developed after fracture were evaluated by determining anterior corpus height compression (ACHC), sagittal index and local kyphosis angle (LKA) with preoperative, post-operative and follow-up radiographs. Anterior corpus height decompression was calculated using the formula described by Mumford et al. [1]. The local kyphosis angle was determined by estimating the Cobb angle between the line passing through the uppermost endplate of the healthy vertebra and the line passing through the lowermost endplate of the lowest healthy vertebra (Fig. 3). The sagittal index was calculated with the measurement described by Farcy et al. [13] (Fig. 4). The correction of spinal canal narrowing due to retropulsed bone fragments was measured from axial CT sections in the immediate post-operative period long term. The mean spinal canal diameter at the levels of the upper and lower healthy vertebrae was measured, and the ideal diameter at the level of the fracture was calculated. The proportion of correction was calculated by dividing the current diameter by the ideal diameter.

Hannover vertebra scores [14], the Oswestry Disability Index [15] and the Visual Analogue Scale (VAS) [16] were filled in for the assessment of function and pain during the final visits of the patients. The joint range of motion was evaluated compared to neutral $\left(0^{\circ}\right)$. Variance analysis relied on repeated measurements to determine statistical significance in terms of the anterior vertebral height compression ratio, local kyphosis angle and sagittal index measurement values in the preoperative, post-operative and follow-up measurements in IS and LS instrumentation. A $p$ value of $<0.05$ was accepted as statistically significant.

\section{Results}

The mean duration between injury and surgery was $24 \mathrm{~h}$. The patients were discharged from the hospital in an 
Fig. 1 a Postero-anterior and b lateral radiographs of a patient with an L1 vertebra fracture who received IS instrumentation
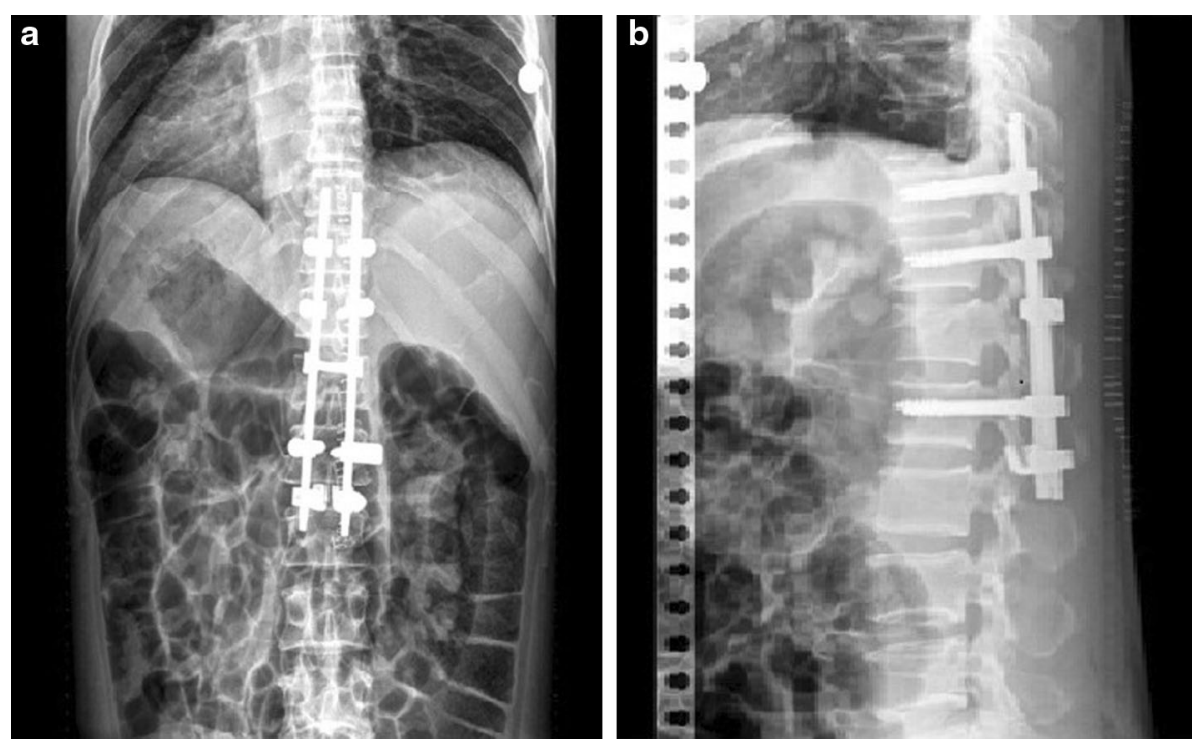

Fig. 2 a Postero-anterior and b lateral radiographs of a patient with a T12 vertebra fracture who received LS instrumentation

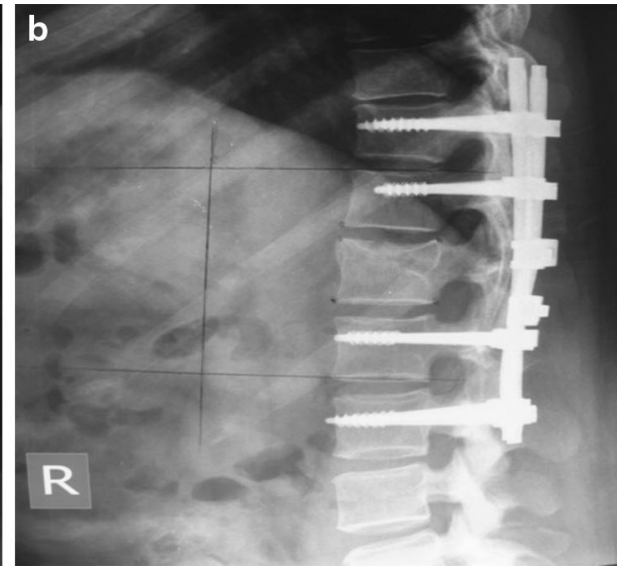

average of 6.3 days. The mean duration of follow-up was 72.3 months in the IS instrumentation group and 70.46 months in the LS instrumentation group.

While the mean sagittal index was 12.84 preoperatively in the IS instrumentation group, it was reduced to -1.01 post-operatively and then increased to 1.9 on final followup radiographs. The sagittal index measured 12.13 preoperatively, -1.01 post-operatively and 1.54 on follow-up radiographs in the LS instrumentation group. Although there was no significant difference between the two groups in terms of sagittal index, preoperative, post-operative and late post-operative follow-up results significantly differed between the two groups $(p=0.128)$. The mean anterior corpus height compression decreased from $36.10 \%$ preoperatively to $12.10 \%$ post-operatively and then increased to $18.80 \%$ at follow-up in the IS instrumentation group. The mean anterior corpus height compression decreased from $34.45 \%$ preoperatively to $11.33 \%$ post-operatively and then increased to $15.63 \%$ on follow-up radiographs in the LS instrumentation group. While the mean LKA measured $15.30^{\circ}$ preoperatively in the IS instrumentation group and $9.62^{\circ}$ in the LS instrumentation group, it was reduced to $1.20^{\circ}$ in the IS instrumentation group and $0.30^{\circ}$ in the LS instrumentation group post-operatively. On follow-up radiographs, the LKA measured $3.15^{\circ}$ in both groups. Statistically significant differences were not found in ACHC or LKA, and the reductions in the degree of correction were also statistically insignificant $(p=0.230$ for ACHC and $p=0.955$ for LKA).

When the diameter of spinal measured preoperatively was compared to post-operative measurements in the long term, the diameter of the spinal canal in the long term postoperatively increased by $48.56 \%$ in group 1 and by $47.01 \%$ in group 2 patients compared to preoperative measurements. The difference between the IS and LS groups was not statistically significant $(p=0.839)$.

Hannover vertebra scoring and the Oswestry Disability Index for the assessment of functionality were completed 


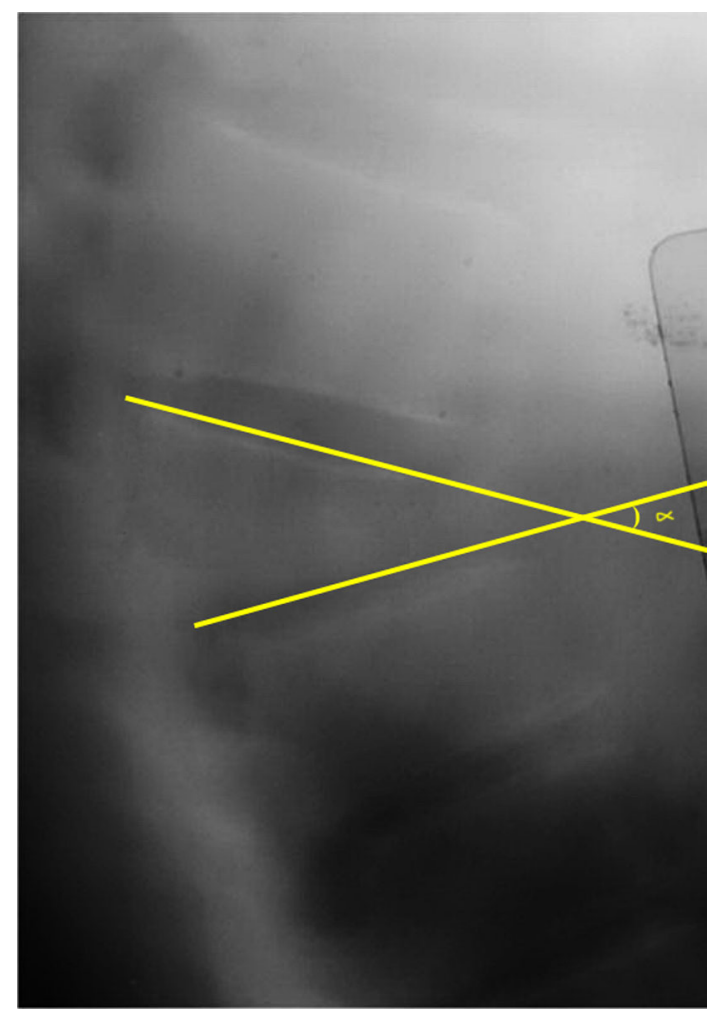

Fig. 3 Sagittal index calculation in the lateral graphs

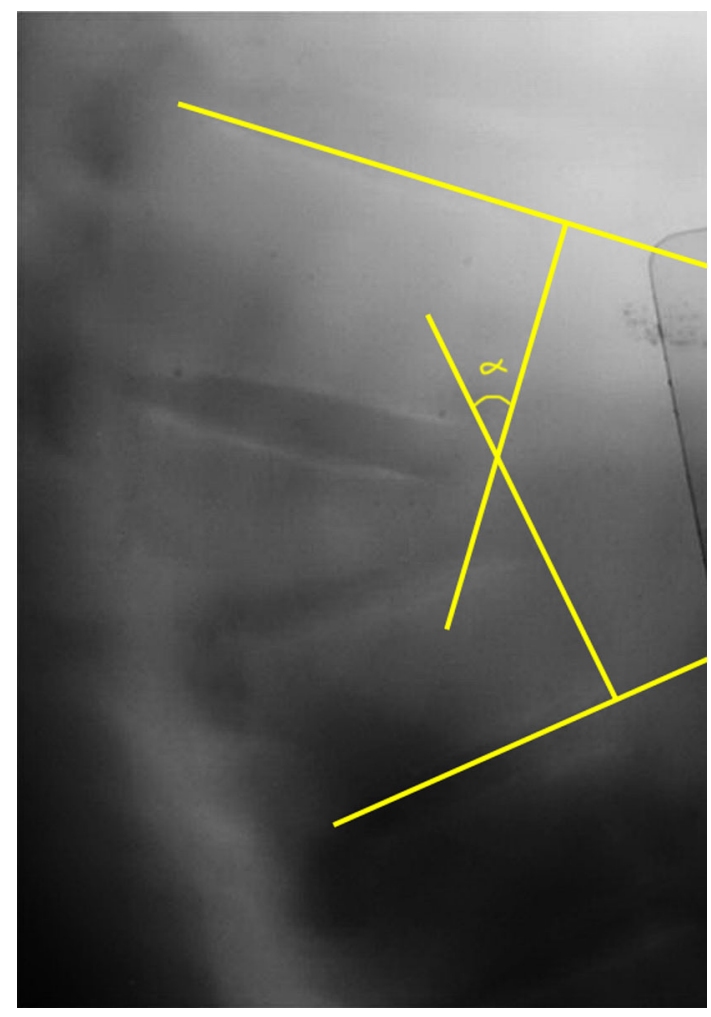

Fig. 4 Calculation of Cobb's angle in the lateral graphs for all patients. The mean Hannover vertebra score was 82 (70-85) in the LS instrumentation group and 62.1 (28-85) in the LS instrumentation group. The mean Oswestry disability score among the ten patients who underwent IS instrumentation was $14.4 \%(12-24 \%)$, and the mean Oswestry disability score of the 15 patients who underwent LS instrumentation was $29.2 \%(12-58 \%)$. In the IS instrumentation group, eight cases $(80 \%)$ reported low disability, two cases $(20 \%)$ reported moderate disability, and there were no reports on severe disability. In the LS instrumentation group, six cases $(40 \%)$ reported low disability, four cases (27\%) reported moderate disability, and five $(33 \%)$ reported severe disability. The difference in long-term Hannover vertebra scores of the patients in the IS and LS groups was statistically significant ( $p=0.07$ ).

Long-term range of motion was compared to neutral $\left(0^{\circ}\right)$. The mean flexion was $66.5^{\circ}$, the extension was $19.5^{\circ}$, the lateral flexion was $20.5^{\circ}$, and the rotation was $30.5^{\circ}$ in the IS instrumentation group; in contrast, the mean flexion was $50.5^{\circ}$, the extension was $10.5^{\circ}$, the lateral flexion was $12.5^{\circ}$, and the rotation was $21.5^{\circ}$ in the LS group. The difference between the groups was statistically significant $(p<0.05)$.

\section{Discussion}

Trans-pedicular, short-segment fixation became popular after the introduction of trans-pedicular screws by RoyCamille et al. [17] and development of the internal fixator by Dick et al. [18]. This approach includes pedicle screw fixation at one vertebra cranial to and one vertebra caudal to the fracture. Although this approach has several advantages, it has been associated with loss of surgical reduction and instrumentation failure.

Instrumentation failure occurs by either of primary mechanisms, implant failure or bony failure. Implant fatigue failure (screw bending or breakage) may occur weeks or months after the initial surgery and typically is observed in the strong, dense bone of young trauma patients [19]. Alternatively, bony failure results in the loosening, toggling or backing out of screws due to failure of the bone. This may occur early or late and is most often observed in older patients with weak osteoporotic bone [20, 21]. In the presence of a thoracolumbar burst fracture, some authors consider augmentation of the vertebral body by anterior column support with cancellous bone, cement, hydroxyapatite blocks grafting or bone graft substitute. Improvement in anterior load-bearing capacity has been reported with trans-pedicular bone grafting [22, 23]. 
In the past few years, a new perspective in the treatment of thoracolumbar trauma was offered with the development of minimally invasive techniques. Their objective is to minimise conventional approach morbidity, such as blood loss, iatrogenic muscle trauma, pain and functional deterioration. It has also been suggested as an adjunct to conventional posterior stabilisation, as it can minimise spinal levels requiring fusion [24]. This technique was shown to have less perioperative morbidity and reduced hospitalisation time. However, implant limitations, increased operative time and an overall more demanding surgical technique are drawbacks that have not permitted widespread acceptance of this method. Posterior percutaneous stabilisation can be used either as a stand-alone procedure or as an adjunct to minimally invasive anterior decompression [25]. Its concept is supported by the reported effectiveness of short-segment fixation and non-fusion techniques in thoracolumbar trauma [26]. In the past, implant characteristics posed several limitations to the technique. Precontoured rods often required the placement of terminal screws with a higher offset, resulting in implant prominence, especially in the thoracolumbar junction [27]. Moreover, insertion of the rods when polyaxial screws were used was technically challenging, while earlier systems did not permit reduction or distraction manoeuvres. Patient and occupational exposure to radiation remains an issue, requiring adequate surgeon education in order to minimise the need for fluoroscopy use [28]. Fusion with minimal posterior surgery is not possible, which necessitates late instrumentation removal [29].

Augmentation of the short-segment pedicle instrumentation (SSPI) construct with offset laminar hooks has been recommended as a means of preventing fixation failure in thoracolumbar fractures [9, 30]. The laminar hooks are thought to decrease the load transmitted between bone and the pedicle screws, thereby protecting both the screws and the bone.

Adding one level of fixation cranially will increase the construct stiffness. Although adding a single motion segment may artificially increase segmental stiffness, to some extent, the protective benefit to pedicle screw bending moments is real. Finally, the addition of a single motion segment cranial to the fracture does not affect the spinal range of motion or sacrifice the principles of SSPI because the thoracic segments are relatively immobile and do not influence the function of the lower lumbar spine [21, 31].

The clinical implications of our findings are that augmentation of an SSPI construct with sublaminar hooks results in a stronger construct while decreasing the bending moments on the screws that might predispose to device failure. Therefore, addition of sublaminar hooks may decrease the rate of clinical failures with SSPI for unstable thoracolumbar fractures while still maintaining the advantages of this system: minimal fusion length, threecolumn fixation and application through a posterior approach [31, 32].

Supplemental offset hooks significantly increased construct stiffness without sacrificing the principles of SSPI (limited lumbar fixation). Furthermore, offset hooks absorb some components of the construct strain, thereby reducing the bending moments transmitted to the screws and reducing the likelihood of screw failure in severely unstable fractures [31].

Some surgeons add pedicle screws at the fractured vertebrae, termed intermediate screws, as part of a shortsegment construct. These screws theoretically may stiffen the construct by splitting the length of the rod that spans from the upper screw to the lower screw into two halflength parts. A shorter rod between two points of fixation will create increased stiffness, and the additional fixation point can theoretically decrease the motion at the metalbone interface. Nevertheless, the true mechanical function of screws inserted into a fractured vertebra is unclear, as the pattern of a burst fracture involves comminution of the vertebral body and separation of the pedicles. To the authors' knowledge, no study has been carried out to show the biomechanical effect of intermediate screws on the fixation of fractures. Dick et al. [18] evaluated the effect of adding screws at the intermediate level on the stiffness of a short-segment construct. Calf spine segments were used and destabilised anteriorly by dividing the disc annulus with a knife. They found that the addition of two intermediate screws increased stiffness in axial loading, flexion and torsion. Because no fracture model was created, no conclusions could be drawn as to the effect of these screws when fixed to a fractured vertebra [32].

In conclusion, the addition of supplemental hooks below the fractured vertebra with trans-pedicular screws inserted into the anterior cortex can result in less motion at the fractured segment within a short-segment construct. Shortsegment fixation offers the advantage of preserving motion segments in the lumbar spine. The authors recommend the use of supplemental sublaminar hooks when posterior spinal fusion is indicated for the fixation of unstable thoracolumbar fractures.

In this study, no statistically significant difference was detected between the groups in terms of long-term functional and radiographic results. Methods supporting anterior column or LS instrumentation are applied to eliminate negative conditions such as the insufficient reduction, reduction loss and inadequate expansion of the spinal canal encountered after short-segment posterior instrumentation [6, 8, 9, 33]. Although LS instrumentation provides stronger fixation and superior spinal canal correction, it results in increased vertebral immobility, as it affects more segments. LS instrumentation has been shown to result in 
more mobile segment immobilisation and more dorsalgia in the future [34, 35]. Therefore, we recommend the IS instrumentation technique, a segment-preserving surgery that has not shown a difference from LS instrumentation either functionally or radiographically.

We recommend future research to compare short-segment and long-segment instrumentation for T12 vertebral fracture, L1 vertebral fracture and L2 vertebral fracture individually.

\section{Conflict of interest None.}

Open Access This article is distributed under the terms of the Creative Commons Attribution License which permits any use, distribution, and reproduction in any medium, provided the original author(s) and the source are credited.

\section{References}

1. Mumford J, Weinstein JN, Spratt KF, Goel VK (1993) Thoracolumbar burst fractures: The clinical efficacy and outcome of nonoperative management. Spine (Phila Pa 1976) 18(8):955-970

2. Hitchon PW, Torner JC, Haddad SF, Follett KA (1998) Management options in thoracolumbar burst fractures. Surg Neurol 49(6):619-626; 626-627

3. Chen HH, Wang WK, Li KC, Chen TH (2004) Biomechanical effects of the body augmenter for reconstruction of the vertebral body. Spine (Phila Pa 1976) 29(18):E382-E387

4. Parker JW, Lane JR, Karaikovic EE, Gaines RW (2000) Successful short-segment instrumentation and fusion for thoracolumbar spine fractures: a consecutive 41/2-year series. Spine (Phila Pa 1976) 25(9):1157-1170

5. Kaneda K, Taneichi H, Abumi K, Hashimoto T, Satoh S, Fujiya M (1997) Anterior decompression and stabilization with the Kaneda device for thoracolumbar burst fractures associated with neurological deficits. J Bone Joint Surg [Am] 79(1):69-83

6. Alanay A, Acaroglu E, Yazici M, Oznur A, Surat A (2001) Short segment pedicle instrumentation of thoracolumbar burst fractures: does transpedicular intracorporeal grafting prevent early failure? Spine (Phila Pa 1976) 26(2):213-217

7. Sanderson PL, Fraser RD, Hall DJ, Cain CM, Osti OL, Potter GR (1999) Short segment fixation of thoracolumbar burst fractures without fusion. Eur Spine J 8(6):495-500

8. Knop C, Bastian L, Lange U, Oeser M, Zdichavsky M, Blauth M (2002) Complications in surgical treatment of thoracolumbar injuries. Eur Spine J 11:214-226

9. McLain RF, Sparling E, Benson DR (1993) Early failure of short segment pedicle instrumentation for thoracolumbar fractures. A preliminary report. J Bone Joint Surg [Am] 75(2):162-167

10. Akbarnia BA, Crandall DG, Burkus K, Matthews T (1994) Use of long rods and a short arthrodesis for burst fractures of the thoracolumbar spine. A long-term follow-up study. J Bone Joint Surg [Am] 76(11):1629-1635

11. Moon MS, Choi WT, Moon YW, Kim YS, Moon JL (2003) Stabilisation of fractured thoracic and lumbar spine with CotrelDubousset instrument. J Orthop Surg (Hong Kong) 11(1):59-66

12. Denis F (1983) The three column spine and its significance in the classification of acute thoracolumbar spinal injuries. Spine (Phila Pa 1976) 8(8):817-831
13. Farcy JP, Weidenbaum M, Glassman SD (1990) Sagittal index in management of thoracolumbar burst fractures. Spine (Phila $\mathrm{Pa}$ 1976) 15(9):958-965

14. Frankel HL, Hancock DO, Hyslop G, Melzak J, Michaelis LS, Ungar GH, Vernon JD, Walsh JJ (1969) The value of postural reduction in the initial management of closed injuries of the spine with paraplegia and tetraplegia. Paraplegia 7(3):179-192

15. Fairbank JC, Pynsent PB (2000) The oswestry disability index. Spine 25(22):2940-2952

16. Wall PD, Melzack R (1989) Methods of testing pain mechanisms in normal man. In: Gracely RH (ed) Textbook of pain. Churchill Livingstone, Singapore, p 257

17. Roy-Camille R, Roy-Camille M, Demeulenaere C (1970) Osteosynthesis of dorsal, lumbar, and lumbosacral spine with metallic plates screwed into vertebral pedicles and articular apophyses. Presse Med 78(32):1447-1448

18. Dick W, Kluger P, Magerl F, Woersdörfer O, Zäch G (1985) A new device for internal fixation of thoracolumbar and lumbar spine fractures: the 'fixateur interne'. Paraplegia 23(4):225-232

19. Shirado O, Kaneda K, Tadano S, Ishikawa H, McAfee PC, Warden KE (1992) Influence of disc degeneration on mechanism of thoracolumbar burst fractures. Spine 17(3):286-292

20. Soshi S, Shiba R, Kondo H, Murota K (1991) An experimental study on transpedicular screw fixation in relation to osteoporosis of the lumbar spine. Spine 16(11):1335-1341

21. Wittenberg RH, Shea M, Swartz DE, Lee KS, White AA, Hayes WC (1991) Importance of bone mineral density in instrumented spine fusions. Spine 16(6):647-652

22. Takami M, Yamada H, Nohda K, Yoshida M (2013) A minimally invasive surgery combining temporary percutaneous pedicle screw fixation without fusion and vertebroplasty with transpedicular intracorporeal hydroxyapatite blocks grafting for fresh thoracolumbar burst fractures: prospective study. Eur J Orthop Surg Traumatol 23. doi:10.1007/s00590-013-1266-2

23. Liao JC, Fan KF, Keorochana G, Chen WJ, Chen LH (2010) Transpedicular grafting after short-segment pedicle instrumentation for thoracolumbar burst fracture: calcium sulfate cement versus autogenous iliac bone graft. Spine (Phila $\mathrm{Pa}$ 1976) 35(15):1482-1488

24. Acosta FL Jr, Aryan HE, Taylor WR, Ames CP (2005) Kyphoplasty-augmented short segment pedicle screw fixation of traumatic lumbar burst fractures: initial clinical experience and literature review. Neurosurg Focus 8(3):e9

25. Assaker R (2004) Minimal access spinal technologies: state-ofthe-art, indications, and techniques. Joint Bone Spine 71(6):459-469

26. Gelb D, Ludwig S, Karp JE, Chung EH, Werner C, Kim T, Poelstra K (2010) Successful treatment of thoracolumbar fractures with short-segment pedicle instrumentation. J Spinal Disord Tech 23(5):293-301

27. Kim YM, Kim DS, Choi ES, Shon HC, Park KJ, Cho BK, Jeong JJ, Cha YC, Park JK (2011) Nonfusion method in thoracolumbar and lumbar spinal fractures. Spine (Phila Pa 1976) 36(2):170-176

28. Rampersaud YR, Annand N, Dekutoski MB (2006) Use of minimally invasive surgical techniques in the management of thoracolumbar trauma: current concepts. Spine (Phila Pa 1976) 31(11):S104

29. Blondel B, Fuentes S, Pech-Gourg G, Adetchessi T, Tropiano P, Dufour H (2011) Percutaneous management of thoracolumbar burst fractures: evolution of techniques and strategy. Orthop Traumatol Surg Res 97(5):527-532

30. Argenson C, Lovet J, de Peretti F, Perraud M, Boileau P, Cambas P, Griffet J (1991) Osteosynthesis of thoracic and lumbar vertebral fractures using Cotrel-Dubousset material (110 cases). Acta Orthop Belg 57(Suppl 1):165-175 
31. Chiba M, McLain RF, Yerby SA, Moseley TA, Smith TS, Benson DR (1996) Short-segment pedicle instrumentation. Biomechanical analysis of supplemental hook fixation. Spine (Phila Pa 1976) 21(3):288-294

32. Anekstein Y, Brosh T, Mirovsky Y (2007) Intermediate screws in short segment pedicular fixation for thoracic and lumbar fractures: a biomechanical study. J Spinal Disord Tech 20(1):72-77

33. Alvine GF, Swain JM, Asher MA, Burton DC (2004) Treatment of thoracolumbar burst fractures with variable screw placement or
Isola instrumentation and arthrodesis: case series and literature review. J Spinal Disord Tech 17(4):251-264

34. Kaya RA, Aydin Y (2004) Modified transpedicular approach for the surgical treatment of severe thoracolumbar or lumbar burst fractures. Spine J 4(2):208-217

35. Tezeren G, Kuru I (2005) Posterior fixation of thoracolumbar burst fracture: short-segment pedicle fixation versus long-segment instrumentation. J Spinal Disord Tech 18(6):485-488 